\title{
Prevalence and patterns of hirsutism among Sri Lankan females
}

\author{
N P Somasundaram ${ }^{1}$, D J S Fernandoㄹ, S Kamaladasa ${ }^{3}$, W K M G Amarawardena ${ }^{4}$
}

Sri Lanka Journal of Diabetes, Endocrinology and Metabolism 2015; 5: 51-55

\begin{abstract}
Objectives: In order to describe the prevalence of hirsutism in young female population of Sri Lanka, we studied a group of young females to determine the pattern of body hair distribution and grade it according to the modified Ferriman-Gallwey score (mFG).

Method: A descriptive cross sectional study was conducted in the year 2000 with eighty-five female medical students who entered the Sri Jayawardenapura University that year. After consent, each subject was interviewed by a medical officer and an interviewer-administered questionnaire was utilized. The body hair distribution was recorded using the $\mathrm{mFG}$ score.

Results: Age of the study population ranged from 21 to 24 years. None of them have used steroids or psoralens prior to study. Only $3(3.5 \%)$ had menstrual irregularity. The mode, Mean and the Median of the total MFG score were 5.0, 8.9 and 9.0 (IQR- 5 to 11) respectively. The prevalence of hirsutism was $56.5 \%$ ( $\mathrm{Cl}$ from 45.96 to 67.04) among the study population. Lower limb score had the highest mean value of 1.80 while Lip score had the lowest mean value of 0.31 . All the 09 variables had statistically significant correlations with the total score while "lower abdomen score" had the strongest correlation of 0.82 .
\end{abstract}

Conclusion: The prevalence of hirsutism among this young female population was relatively high (56.5\%). They were seen to have a high degree of hair growth in all the areas tested on $\mathrm{mFG}$ score. The lower abdominal area had the strongest correlation with the mFG score. As many factors including genetic predisposition determine hirsutism this has to be considered when evaluation of young females for hirsutism.

\section{Introduction}

Hirsutism is defined as the presence of excessive terminal (coarse) hair in androgen-dependent areas of the female. It has been found that hirsutism negatively influences psychological well-being (2). Hirsutism is usually caused by benign functional conditions (idiopathic hirsutism), polycystic ovary syndrome, but may be the presenting symptom of a malignant tumor requiring immediate intervention. The prevalence of hirsutism is around $10 \%$ in most populations (3). The prevalence of hirsutism among Sri Lankan females is unknown. Studies demonstrate racial and genetic variation of hair distribution in females; Sri Lankan and Middle Eastern ethnic being hairier. Several hirsutism scores for women have been proposed based on visual assessment of hair type and growth (4-8).

Out of these methods, the modified Ferriman-Gallwey score ( $\mathrm{mFG}$ ) proposed by Hatch et al. is considered as the gold standard for the evaluation of hirsutism (9). This method uses 9 body areas. If there is no terminal hair growth a score of zero is given. Minimally visible terminal hair growth is given a score of 1 , score of 2 is given if hair growth is more than minimal, a score of 3 is that of a not very hairy male while a score of 4 is what's typically observed in well-virilized healthy adult male. A recommended cut-off value to define hirsutism is the 95th percentile of the $\mathrm{mFG}$ score of the relevant general population ethnicity (3). When this value is unavailable, a cut-off value of 8 or above is applied to White and Black women, while for Far East and South East Asian women this is decreased to three or above.

However modified Ferriman-Gallwey score (mFG) was not validated locally for the evaluation of hirsutism. It should also be noted that the mFG scoring system gives an estimation of the total amount of body hair, and not that of the regional distribution of the excessive hair growth. The validity of this system on Sri Lankan population has not been fully evaluated.

${ }^{1}$ Department of endocrinology, National hospital of Sri Lanka, ${ }^{2}$ Sherwood forest hospitals, NHS, UK, ${ }^{3} 52$, Boundary road, Dubbo NSW 2830, Australia, ${ }^{4}$ Colombo north teaching hospital, Sri Lanka. 


\section{Justification}

Detecting hirsutism with a cost-effective method yield physiological as well as psychological benefits for women. It helps early identification of treatable conditions. As documented local literature is not common, this study evaluates the burden of hirsutism in relation to local context. Several previous observational studies have suggested that specific body areas may be more related to total body hirsutism than others $(9,10)$. Therefore evaluation of individual parameters of $\mathrm{mFG}$ score and their correlation would enable the future researches to decide on required modifications for a locally validated tool to screen for hirsutism.

\section{Objectives}

The objectives were to determine the prevalence of hirsutism among a group of young females, to determine the pattern of body hair distribution and grade them on $\mathrm{mFG}$ system and to describe correlation between individual parameters in the $\mathrm{mFG}$ with the total $\mathrm{mFG}$ score.

\section{Methods}

A descriptive cross sectional study was done after obtaining the ethical approval from the ethical review committee of University of Sri Jawardenapura. Study population was female medical students who entered the Sri Jayawardenepura University in the year 2000. Study setting was the routine medical screening that is performed for the entrants at the university medical centre. The total population of female medical students in that particular batch was taken to the study. Therefore eighty five female medical students participated in the study. Each subject was interviewed by a medical officer and an intervieweradministered questionnaire was utilized. The data collection tool comprised of a past medical history component and an examination component. The former included details about the use of long-term drug therapy (steroids, psorelens), and menstrual pattern. Irregular cycles were defined when the cycle length is more than 35 days. The latter component included the BMI calculation and the 09 parameters to calculate the mFG score. For detailed analysis, BMI cut off values suggested by Sri Lanka Endocrine Society based on Asian data were used. The participants were asked about their practices on cosmetic removal of body hair. The parameters for modified FG score included the grading of hirsutism of lip, chin, chest, upper abdomen, lower abdomen, upper limb, lower limb, upper back and of the lower back. The standard methodology mentioned in the section 1.1 was used in grading.

Data was entered in to a database and analysis was conducted in Statistical Package for Social Sciences (SPSS) version 16. The cutoff of mFG score was taken as 08 and the prevalence was expressed as a percentage.
Descriptive analysis was done on the numerical score variables for each parameter and the total FG score. Correlation analysis was done using Spearman correlation coefficient. Significance of the mean scores of the groups with and without hirsutism (as detected by the modified FG score) was evaluated by Mann-Whitney U test.

\section{Results}

A total of eighty five female medical students were included in the survey. Age of the study population ranged from 21 to 24 years. Among them 84 students were unmarried and one student was married.

Table 1 summarizes the findings for the variables of past medical history. None of them have used steroids or psoralens prior to study. Only 3.5\% $(\mathrm{n}=3)$ had menstrual irregularity.

\section{Table 1. Distribution of parameters in past medical history}

\begin{tabular}{llll}
\hline Variable & $\begin{array}{l}\text { Yes } \\
N(\%)\end{array}$ & $\begin{array}{l}\text { No } \\
N(\%)\end{array}$ & $\begin{array}{l}\text { Total } \\
N(\%)\end{array}$ \\
\hline $\begin{array}{l}\text { Used steroids } \\
\text { or psoralens }\end{array}$ & $00(0)$ & $85(100)$ & $85(100)$ \\
$\begin{array}{l}\text { Irregular } \\
\text { menstruation }\end{array}$ & $03(3.5)$ & $82(96.5)$ & $85(100)$ \\
\hline
\end{tabular}

Table 2 shows the distribution of BMI. Total of 57 students participated for BMI assessment, out of which only 3 were obese. (5.3\%) (Table 2). None of the obese females had menstrual irregularities. Four participants were using hair removing methods for cosmetic purposes. The minimum value of modified Ferriman-Gallwey score (mFG) was 2 and the maximum was 21. The Mode, Mean and the Median of the total score were 5, 8.9, and 9.0 respectively. (IQR- 5 to 11) Figure 1 depicts the distribution of mFG scores. The distribution curve was skewed to the right with $56.5 \%$ having a score $\geq 8$.

Table 2. Distribution of BMI

\begin{tabular}{lcc}
\hline BMI category & Frequency & Percentage \\
\hline Underweight $(<18.5)$ & 5 & 8.8 \\
Normal $(18.5-22.9)$ & 26 & 45.6 \\
Overweight $(23-24.9)$ & 23 & 40.4 \\
Obese (equal or $>25)$ & 3 & 5.3 \\
Total & $57^{*}$ & 100.0 \\
\hline
\end{tabular}

*Missing data in BMI assessment was 29 
Fourty eight students had score of 8 or more in modified Ferriman-Gallwey score (mFG), giving a hirsutism prevalence of $56.5 \%$ (CI from 45.96 to 67.04) amongst the study population. None of them had other features of virilization on physical examination.

Table 3. Descriptives of individual $\mathrm{mFG}$ parameters and their correlation with total $\mathrm{mFG}$ score

\begin{tabular}{|c|c|c|c|c|}
\hline $\begin{array}{l}\text { Parameter } \\
\text { (Score at } \\
\text { examination } \\
\text { site) }\end{array}$ & Mean & Median & $\begin{array}{r}\text { Spearman } \\
\text { Correlation } \\
\text { with total } \\
\text { score }\end{array}$ & $\begin{array}{r}\text { Significance } \\
\text { p value }\end{array}$ \\
\hline Upper Lip & 0.31 & 0 & 0.49 & $<0.001$ \\
\hline Chin & 0.35 & 0 & 0.40 & $<0.001$ \\
\hline Chest & 1.18 & 1 & 0.77 & $<0.001$ \\
\hline Upper abdomen & 1.18 & 1 & 0.77 & $<0.001$ \\
\hline Lower Abdomen & 1.46 & 1 & 0.82 & $<0.001$ \\
\hline Upper limb & 1.53 & 1 & 0.49 & $<0.001$ \\
\hline Lower limb & 1.80 & 2 & 0.70 & $<0.001$ \\
\hline Upper back & 0.34 & 0 & 0.53 & $<0.001$ \\
\hline Lower back & 0.47 & 0 & 0.54 & $<0.001$ \\
\hline
\end{tabular}

Table 3 summarizes the means, medians and correlations with total score, of the 09 variables of mFG score. Lower limb score had the highest mean value of 1.80 while Lip score had the lowest mean value of 0.31 . All the 09 variables had statistically significant correlations with the total score while "lower abdomen score" had the strongest correlation of 0.82 . Chin score had the lowest correlation with the total score.

All the parameters of the mFG score had a significant association with the hirsutism status (either presence or absence).

\section{Table 4. Association between hirsutism status and parameres of $\mathrm{mFG}$ score}

\begin{tabular}{lrrr}
\hline $\begin{array}{l}\text { Parameter } \\
\text { Score at } \\
\text { examination } \\
\text { site) }\end{array}$ & $\begin{array}{r}\text { Mean rank } \\
\text { Hirsutism }\end{array}$ & $\begin{array}{r}\text { No } \\
\text { Hirsutism }\end{array}$ & $\begin{array}{r}\text { Signifi- } \\
\text { cance* } \\
\text { p value }\end{array}$ \\
\cline { 2 - 4 } Upper Lip & 48.38 & 36.03 & 0.002 \\
Chin & 47.43 & 37.26 & 0.020 \\
Chest & 55.18 & 25.91 & $<0.001$ \\
Upper abdomen & 56.18 & 25.91 & $<0.001$ \\
Lower Abdomen & 57.32 & 24.42 & $<0.001$ \\
Upper limb & 50.83 & 32.84 & $<0.001$ \\
Lower limb & 55.49 & 26.80 & $<0.001$ \\
Upper back & 50.56 & 33.19 & $<0.001$ \\
Lower back & 51.51 & 31.96 & $<0.001$ \\
\hline
\end{tabular}

*Using Mann Whitney U test

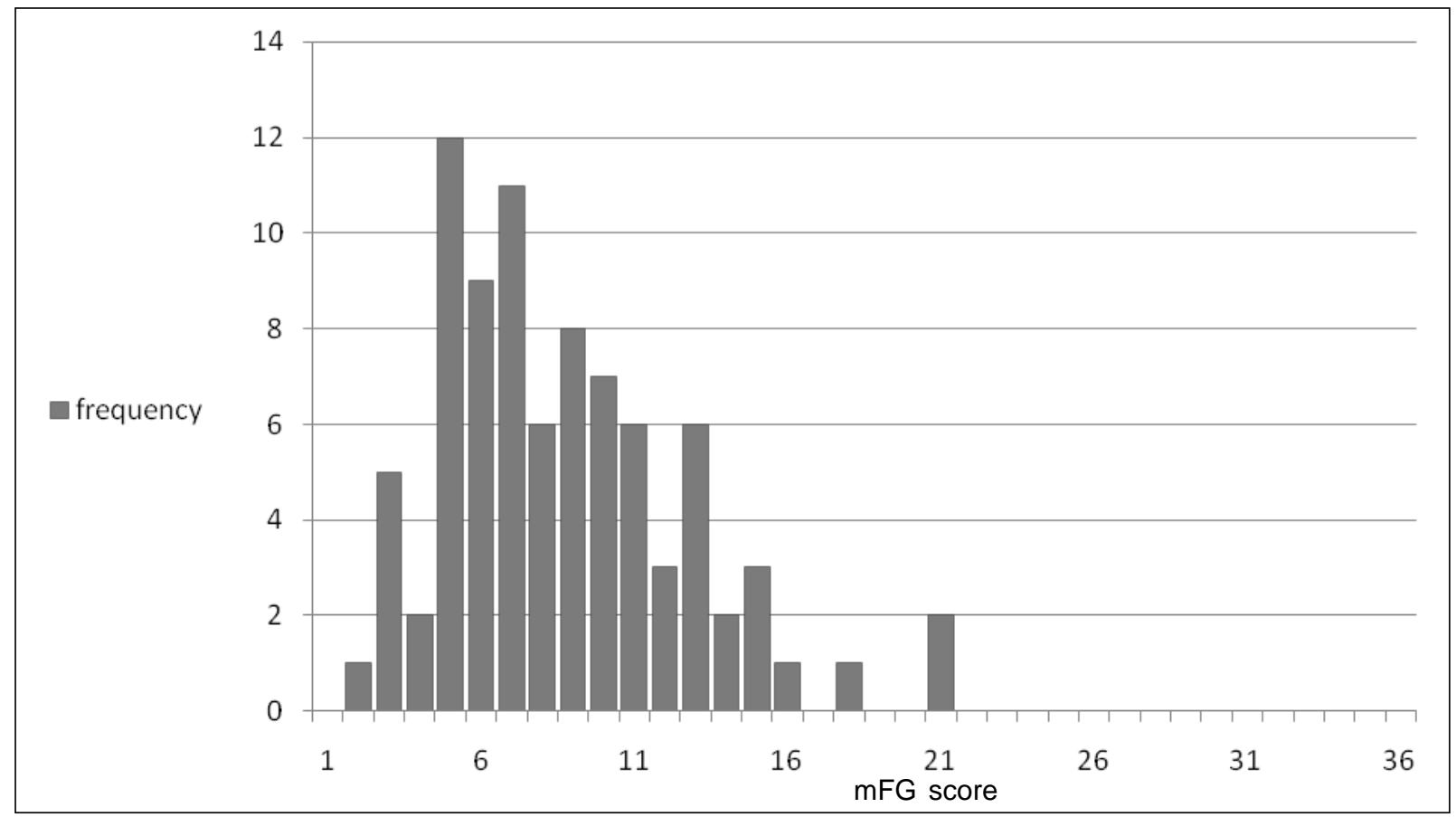

Figure 1. Distribution of $\mathrm{mFG}$ scores 


\section{Discussion}

In our study only 3 students were found to have obesity according to the revised Sri Lankan obesity guideline cutoff, and only 3 students had menstrual irregularities. None of the obese females had menstrual irregularities. Therefore the study population was considered as a relatively healthy population and further investigations for PCOD and other rare causes for hirsutism was not carried out. However, not continuing with tests to exclude an underlying pathology is a short coming of this study.

Most studies reveal the prevalence of hirsutism around $10 \%$ in most populations. Indian study by Zargar et al. (2002) showed a prevalence of $10.5 \%$ (11). A Spanish study by Asuncion et al. (2000), Turkish study by Sagsoz et al. (2004), USA study by DeUgarte et al. (2006), Iran study by Noorbala and Kefaie (2010) described a prevalence of $7.1 \%, 8.3 \%, 5.4 \%, 10.8 \%$ respectively (12-15). An Australian study done by March et al. (2010) showed a higher prevalence of $21.2 \%$ in a white Caucasian population (16). All the studies have used mFG score to assess hirsutism.

Our study showed a higher prevalence of 56.5\%. Racial difference in prevalence of hirsutism as well as inter observer variability in recording the mFG score can be contributing factors for this difference. Poor validity of the cut off used can be another cause for this higher value of hirsutism. Therefore it highlights the importance of a locally validated cut off for the mFG for Sri Lanka rather than using a blanket cut off of 8 .

In our study subjects had $\mathrm{mFG}$ scores ranging from 2 to 21 . The most frequently affected site was the lower limb, but the most densely affected area was also found to be the lower limb. In a study on assessment of hirsutism among Korean women showed that the most frequently affected site was the upper back, but the most densely affected area was the lower abdomen (17).

Our study also showed a statistically significant association between hirsutism score and the individual means of nine body sites.

In our study, the strength of correlation between the total score and the individual nine parameters showed diversity from 0.40 to 0.82 . But the abdominal score had the strongest correlation with the total mFG score. In a similar study by Homeira Rashidi et al showed that evaluation of terminal hair growth on the chin or lower abdomen has a high sensitivity for predicting hirsutism. (18). Knochenhauer ES et al also found that hair growth score of 2 or more on the chin or lower abdomen only was found to be a highly sensitive predictor for hirsutism in high-risk populations with an expected hirsutism prevalence of $>20 \%(10)$.

\section{Conclusions}

The prevalence of hirsutism among a group of female university entrants to Sri Jayawardenapura University was $56.5 \%$ (CI from 45.96 to 67.04). All the nine parameters of the $\mathrm{mFG}$ score are significantly associated with the final hirsutism score $(p<0.05)$. Out of them strongest correlation was observed with the lower abdominal score (Spearman correlation coefficient -0.82 ).

\section{Recommendations}

A larger population based study to determine the normative data for Sri Lankan women is a priority and will help develop age standardized data. Minimizing the number of examiners and training examiners prior to evaluation of the score will be helpful to minimize interobserver variation. Use of photographic representation of mFG scoring system will also be helpful to reduce interobserver variation.

\section{References}

1. Shlomo M, Kenneth P, Larsen PR, Kronenberg HM. Williams Textbook of Endocrinology.12th Ed. ElesevierSaunders 2011: 618-9.

2. Barth JH, Catalan J, Cherry CA, Day A. Psychological morbidity in women referred for treatment of hirsutism. $J$ Psychosom Res 1993; 37: 615-9.

3. Morreale HFE et al. Human Reproduction Update 2012; 18: $146-70$.

4. Shah PN. Human body hair: a quantitative study. Am $J$ Obstet Gynecol 1957; 73: 1255-65.

5. Ferriman D, Gallwey JD. Clinical assessment of body hair growth in women. J Clin Endocrinol Metab 1961; 21: 1440-7.

6. Moncada E. Familial study of hirsutism. J Clin Endocrinol Metab 1970; 31: 556-64.

7. Hatch R, Rosenfield RL, Kim MH, Tredway D. Hirsutism: implications, etiology, and management. Am J Obstet Gynecol 1981; 140: 815-30.

8. Practice Committee of the American Society for Reproductive Medicine. The evaluation and treatment of androgen excess. Fertil Steril 2006; 86: S241-S247.

9. Knochenhauer E, Hines G, Conway-Myers B, Azziz R. Examination of the chin or lower abdomen only for the prediction of hirsutism. Fertl Steril 2000; 74: 980-3.

10. Lunde O, Grottump P. Body hair growth in women: Normal or hirsute. Am J Anthropol 1984; 64: 307-13.

11. Zargar AH, Wani AI, Masoodi SR, et al. Epidemiological and etiological aspects of hirsutism in Kashmiri women in the Indian subcontinent. Fertl Steril 2002; 77: 674-8.

12. Asuncion M, Calvo RM, San Millan JL, Sancho J, Avila S, Escobar-Morreale HF. A prospective study of the prevalence of polycystic ovary syndrome in unselected Caucasian women from Spain. J Clin Endocrinol Metab 2000; 85: 2434-8. 
13. Sagsoz N, Kamaci M, Orbak Z, Body hair scores and total hair diameters in healthy women in the Kirikkale Region of Turkey. Yonsei Med J 2004; 45: 483-91.

14. DeUgarte CM, Woods KS, Bartolucci AA, Azziz R. Degree of facial and body terminal hair growth in unselected black and white women: toward a populational definition of hirsutism. J Clin Endocrinol Metab 2006; 91: 1345-50.

15. Noorbala MT, Kefaie P. The prevalence of hirsutism in adolescent girls in Yazd, Central Iran. Iran Red Crescent Med J 2010; 12: 111-7.
16. March WA, Moore VM, Willson KJ, Phillips DI, Norman RJ, Davies MJ. The prevalence of polycystic ovary syndrome in a community sample assessed under contrasting diagnostic criteria. Hum Reprod 2010; 25: 544-51.

17. Yildiz BO, Bolour S, Woods K, Moore A, Azziz R. Visually scoring hirsutism. Hum Reprod Update 2010; 16: 51-64.

18. Rashidi H, Parizi Z T, Mohammadi M. Evaluation of only the chin or lower abdomen for predicting hirsutism. Indian J Endocrinol Metab 2013; 17(5): 896-8. 